\title{
Design of compressed natural gas-air mixer for dual fuel engine using three- dimensional computational fluid dynamics modeling
}

\begin{abstract}
In diesel-compressed natural gas (CNG) dual fuel systems, the CNG is generally inducted into the intake manifold by a CNG mixer mounted at the intake manifold, while the diesel fuel is directly injected into the engine cylinder using a diesel fuel injector system. The poor mixing performance of gaseous mixers is among the causes of unsatisfactory engine performance and lethal exhaust emissions. Based on an existing mixer model, four different models of mixers with 29 cases were created in this study to investigate the effects of the diameter, location, and number of holes inside the existing mixer on the homogeneity and distribution of the mixture. A computational fluid dynamics analysis software was used to check the flow behavior of the CNG and air inside the existing and new mixer models, with the new model being fixed on a 3.2 L engine. These models were examined depending on the maximum speed of the engine (4000 rpm), the full-opened valve, and the stoichiometric airfuel ratio (34.6). Compared with the new mixer models, the existing mixer model shows a non-uniform methane and air distribution. Model 4/case 26 shows a uniform distribution of the CNG-air mixture with the best homogeneity. This model was then examined to check the flow characteristics of CNG and air at different engine speeds (1000, 2000, 3000, and 4000 rpm). Model 4/case 26 also shows a stoichiometric air-fuel ratio depending on the engine speed.
\end{abstract}

Keyword: AIR-CNG mixer; Computational fluid dynamics (CFD); Dual fuel engine; Homogeneity of the mixture 